\title{
Las maquiladoras y las mujeres en Ciudad Juárez, paradojas de la industrialización bajo el capitalismo integral
}

\author{
María Patricia Fernández \\ Centro de Estudios Fronterizos del Norte de México
}

\begin{abstract}
Resumen
A lo largo de este trabajo se explican los factores que afectan el empleo de la mujer en la industria maquiladora fronteriza. Este ensayo es un intento por demostrar que el trabajo de las maquiladoras en la frontera es un proceso de descalificación y feminización del trabajo; que la coexistencia del trabajo fabril femenino y las altas tasas de desempleo y subempleo masculino que caracterizan a los mercados de trabajo de la frontera mexicana, no debe tomarse a la ligera, ya que esta combinación genera falsas imágenes de crecimiento económico sin un mejoramiento real de las condiciones materiales en que viven miles de familias trabajadoras. Para comprender la expansión del programa de maquiladoras es necesario tomar en cuenta aspectos tales como la creciente fluidez del capital transnacional y la posición que guardan ciertas industrias en el contexto mundial. Mano de obra abundante y barata y una situación política estable, son algunos de los factores que han estimulado el traslado de producción de los países hegemónicos como Estados Unidos a zonas periféricas como la frontera mexicana.
\end{abstract}

Palabras clave: maquiladoras, feminización del trabajo, subempleo y desempleo, organización familiar, flujo migratorio.

\begin{abstract}
Factors affecting the employment of women in the border maquila industry are thoroughly explained along this document. This essay tries to prove that the border maquila job is a process to disqualify and feminize jobs; that we should seriously consider the co-existence of feminine industry labor and high unemployment rates as wells as male underemployment that characterize labor market on the Mexican border, because this combination creates fake images of economical growth without a true improvement of life conditions that live thousands of working families. To understand the growth of the maquila program, it is necessary to consider such aspects as the growing flow of trans-national capital and the position of certain industries within the world context. Among some of the causes to translating production from hegemonic countries as the United States to peripheral zones like the Mexican border we find that there is plenty of cheap manpower along in a stable politic environment.
\end{abstract}

Keywords: maquila industries, feminization of jobs, underemployment and unemployment, family organization, migration flow. 


\title{
LAS MAQUILADORAS Y LAS MUJERES EN CIUDAD JUAREZ. PARADOJAS DE LA INDUSTRIALIZACION BAJO EL CAPITALISMO INTEGRAL
}

\author{
Maria Patricia Fornández \\ Antropóloga Social, Ph. D. de la Universidad de Rutgers, \\ Investigadora del Programa de Estudios México-Estados Unidos, \\ Universidad de California, San Diego y Centro de Estudios \\ Fronterizos del Norte de México \\ Tij uana, Baja California
}

\section{INTRODUCCION}

Cuando se camina a lo largo de las calles proletarias de la colonia Zacatecas en Ciudad Juárez, Chihuahua es posible ver sin dificultad la imagen transparente del centro de El Paso, Texas; sus modernos edificios claramente trazados contra el escenario de las montañas Franklin forman agudo contraste con el deprimente contexto en el que viven miles de trabajadores mexicanos.

Las ciudades son expresión viviente de la conformación política y económica de la sociedad. La historia les da forma e imprime en su semblante el legado de desigualdades seculares. Apenas separadas por una tenue línea internacional de demarcación. El Paso y Ciudad Juárez sintctizan la relación asimétrica que ha existido por más de cien años entre Estados Unidos y México.

Para los mexicanos que tratan de cruzar la frontera ilegalmente, El Paso ofrece la promesa de salarios elevados. mejores oportunidades de empleo y acceso a una amplia gama de símbolos de prosperidad: un sueño de movilidad social ascendente basado en el consumo. A toda hora hombres y mujeres se sientan a la orilla del estrecho canal que divide a las dos ciudades con el cuerpo suspendido aún en territorio mexicano. y los pies columpiándose ya en Estados Unidos. Paciente o audazmente retan a la omnipresente migral esperando el momento de cruzar sin ser vistos. Muchos son detenidos y deportados inmediatamente; muchos volverán a intentar el paso a la tierra prometida.

La realidad es muy distinta para los ejecutivos norteamericanos que se trasladan a Ciudad Juárez desde los elegantes suburbios de El Paso. Para ellos la ciudad mexicana es un creciente complejo industrial, testimonio de un "nuevo orden económico internacional" cuyo principal rasgo es la "alianza" del capital monopólico (Helliner, 1973) con la fuerza laboral descubierta en países periféricos y semiperiféricos. Muchos de estos ejecutivos trabajan como

1 Término utilizado en español vernáculo para referirse al Servicio de Inmigración y Naturalización de Estados Unidos. 
gerentes en más de ciento treinta "maquiladoras"2 existentes actualmente en Ciudad Juárez. Son éstas, plantas de ensamblaje que dependen de corporaciones transnacionales con sede en Estados Unidos. Muchas operan como subsidiarias, otras como empresas subcontratadas. Más de la mitad de estas fábricas elaboran productos eléctricos y electrónicos mientras que aproximadamente el $30 \%$ se dedican a la producción de prendas de vestir. El resto están orientadas a operaciones diversas que incluyen la clasificación de cupones, la producción de tela de asbesto, el ensamblaje de aerosoles plásticos, juguetes y productos ornamentales. La mayoría de quienes trabajan en estas fábricas son mujeres mexicanas cuya edad predominante fluctúa entre los 17 y los 25 años. Rosario Rivera,de 18 años,es una de tales mujeres.

Tras de ser abandonada por su joven esposo después de dos años de matrimonio, Rosario fue a vivir con su madre, Mariana, su hermano menor, Gerardo, y sus dos tías, Francisca y Julia. Las dos últimas trabajan como operadoras directas de producción en maquiladoras de ropa. Francisca y Julia trabajan para mantenerse a sí mismas y a sus dos hijos. Rosario trabaja con la esperanza de mudarse a una casa digna y para brindar a su hermano la educación que ella no pudo obtener. Actualmente vive con sus familiares en una casa de adobe de dos cuartos con permanentes goteras, en la colonia Zacatecas. La renta mensual por este modesto alojamiento es de casi 60 dólares. A pesar de su juventud, Rosario vive pendiente de la situación hogareña:

- Cuando veo a mi madre y a mis tías reir y platicar, quisiera que siempre estuvićramos contentas. Pero la verdad es que tenemos muchos problemas. Mi madre quiere cambiarse a un lugar distinto porque el barrio está lleno de vagos. Se paran en las esquinas fumando mariguana, tomando, jugando rayuela y acosando a los transeúntes. ique maldición! Es que no tienen en que ocuparse. Hay muchos hombres desempleados en esta ciudad. . .

- Mi madre hace lo posible por atender la casa y los niños, porque ni Francisca ni Julia tienen los medios para pagar su propio alojamiento. Por una parte las comprendo: ¿quién querría hacerse cargo de sus hijos si viviesen solas? Por otra parte nosotros tenemos que tolerar sus exigencias y malos humores; creen tener derechos especiales porque contribuyen con el gasto familiar. A veces eso les pasa a las mujeres que trabajan; jacaban portándose como hombres!

-Tanto Francisca como Julia ya vivían aquí cuando me fui con Carlos. El fue mi última esperanza; quería casarme porque creía que mi situación sólo podría mejorar. Carlos era entonces estudiante de arquitectura. La prime-

2 El artículo 321 del código de aduanas de México define una maquiladora como una empresa industrial que 1) con maquinaria temporalmente importada sin importar los costos de producción, exporta el total de su producción 0,2 ) con una planta industrial ya establecida para suplir al mercado doméstico dirige parte o la totali. dad de su producción a la exportación; y cuyo costo directo de manufactura de la producción al momento de la exportación no excede el $40 \%$. Ver Bustamante, 1976. 
ra vez que salimos me llevó al café "Europa" y me pidió fresas con crema. Me comí dos porciones tal como una señora elegante en una novela romántica. A los 16 años quedé embarazada y nos casamos poco después. Las cosas cambiaron. Aún antes de la muerte de mi bebé, Carlos ya había comenzado a beber; dejó de ir a la escuela y no me pudo mantener. Cuando se fue no tuve otra alternativa que buscar trabajo en planta. Tuve suerte de encontrar empleo en RCA. Estaban aumentando la producción y contratando personal; puras mujeres.

- Conozco muchas muchachas que no pueden encontrar trabajo en las maquiladoras por falta de educación pero yo cursé primaria, secundaria y comercio. Antes tenía la ilusión de trabajar como recepcionista o secretaria pero para eso se necesita saber inglés así es que mi destino es trabajar como operadora hasta que el cuerpo aguante. .

-Mi turno comienza a las 6:30 de la mañana y termina a las 3:30 de la tarde de lunes a viernes. Los sábados trabajamos de 6:30 a 11:30 de la mañana, es decir 48 horas a la semana. Cada viernes recibo 1,001 pesos (un poco menos de 43 dólares). Le doy a mi mamá la mitad de mi salario. Con el resto pago "ruteras" 3 comidas y gastos personales. Ahora estoy comprando una consola con radio, tocadiscos y tocacintas. Por lo menos eso puedo comprar con mi propio dinero. Mientras que pueda trabajar no creo que vuelva a casarme.

\section{LAS MAQUILADORAS Y LA DIVISION SEXUAL DEL TRABAJO.}

Existe gran variación en las experiencias personales de cada individuo. Sin embargo, la anterior historia no difiere notablemente de la de miles de mujeres empleadas en las maquiladoras fronterizas. Como muchas otras, Rosario es joven, soltera y sin hijos. Carece de apoyo económico por parte de padre o esposo y tiene grandes necesidades económicas. Al igual que otras mujeres dedicadas al trabajo de maquila en Ciudad Juárez -especialmente aquellas empleadas en la industria del vestido-Rosario pertenece a una familia de puras mujeres. Más frecuente aún es el caso de las jóvenes que trabajan para mentener a sus padres y hermanos. Aunque muchos padres, esposos, hermanos y otros parientes del sexo masculino cohabitan frecuentemente con estas mujeres, los datos que arroja la investigación indican que la mayor parte de estos varones se encuentran desempleados o subempleados. Tal como se

\footnotetext{
3 Las "ruteras" son camionetas pequeñas adaptadas para ser usadas como transporte público en Ciudad Juárez. A pesar de su lamentable estado cubren el $85 \%$ de la ciudad y son, por tanto, el sistema de transportación más comunmente usado por las obreras de maquiladoras.
} 
verá a continuación, las espontáneas palabras de Rosario acerca de sí misma y su familia constituyen un análisis superficial pero acertado de los dilemas y alternativas que las mujeres en ciudades fronterizas enfrentan actualmente.

Considerando el cotexto de América Latina, en el cual una de cada tres mujeres asalariadas trabajan como domésticas, las obreras de las maquiladoras representan un fenómeno relativamente reciente y poco común. Del $19.4 \%$ de mujeres empleadas en la industria mexicana, solo el $0.7 \%$ laboran como obreras directas de producción. (González Salazar, 1976). En contraste y como resultado de las operaciones de las maquiladoras, casi la mitad de la fuerza laboral de Ciudad Juárez está formada por mujeres. Esto no es casual; se trata más bien de un síntoma característico de las tendencias actuales que aparecen a escala mundial y que afectan la división internacional del trabajo. Ciertamente, mujeres como Rosario son las portadoras del trabajo buscado por el capital monopólico para formar "alianza" en un nuevo y peculiar orden económico.

Para comprender cabalmente la experiencia de Rosario no es suficiente el describir las vicisitudes de su historia personal. Debe intentarse el análisis de los factores económicos y políticos, configurados históricamente, que han generado la contratación masiva de mujeres por parte de las maquiladoras. Una investigación de las maquiladoras debe incluir dos etapas:

a) El análisis de las condiciones estructurales que han determinado la movilización de centros y etapas productivas de países hegemónicos (tales como Estados Unidos) a zonas geográficas periféricas y semiperiféricas (tales como la frontera mexicana), y

b) el examen de las condiciones concretas que han precipitado la inserción de un sector específico de la población (cn este caso las mujeres) a la fuerza de trabajo industrial. A continuación abordaré ambos puntos.

Los orígenes inmediatos de las maquiladoras se encuentran en la implementación del Programa de Industrialización de la Frontera, iniciado en 1965. y en otros esfuerzos gubernamentales llevados a cabo en años posteriores. Tales programas han hecho posible la colaboración de compañías transnacionales con capitalistas mexicanos y representantes del sector público para apoyar el desarrollo de la industria de exportación a lo largo de la frontcra mexicana.

La importancia de este programa en años recientes se puede apreciar al subrayar que las maquiladoras representan actualmente más de la mitad de las importaciones de Estados Unidos procedentes de países en desarrollo bajo disposiciones arancelarias que regulan la industria de ensamblaje. En 1970 la cifra equivalente llegaba únicamente al $10 \%$. (Newton y Balli. 1979). 
En 1978 las maquiladoras aportaron a la economía mexicana más de 95,000 empleos y 713 millones de dólares en valor agregado. Así, ese año solamente 1a industria del turismo y la petrolera rebasaron en importancia a las maquiladoras. Los 95,000 trabajadores empleados en ellas recibieron aproximadamente una tercera parte del valor agregado. El resto penetró a la economía nacional en forma de rentas, impuestos, costos de materia prima y gastos diversos.

Las condiciones objetivas que han determinado el crecimiento de la industria maquiladora son consecuentes con la mentalidad capitalista contemporánea. En otras palabras, las maquiladoras reflejan la tendencia hacia la penetración del capital internacional en las economías locales, y una acentuación de la integración de países periféricos y semiperiféricos al comercio internacional. Dicha penetración se ha dado a través de corporaciones transnacionales que buscan bajos salarios, disponibilidad de lo que aparenta ser una inagotable reserva de trabajo no calificado y semicalificado, altos niveles de productividad y una dócil fuerza de trabajo. Por ejemplo, al decir de muchos inversionistas, el incremento de la productividad por hora/hombre a lo largo de la frontera mexicana (al ser comparada con industrias semejantes en Estados Unidos) ha fluctuado entre el 10 y el $15 \%$. Esta cifra incluye cálculos sobre ausentismo de los trabajadores en ambos países, cuya comparación también ha sido favorable a México. (Newton y Balli, 1979, pp. 11-12; Konig, 1979; Campero y Guerrero, 1977).

En reuniones tanto públicas como privadas, los representantes de las grandes y medianas empresas han exaltado las múltiples ventajas que resultan de la inversión transnacional en operaciones de ensamblaje realizadas en países en desarrollo. Por su parte, los funcionarios públicos mexicanos han preferido enfatizar los supuestos beneficios económicos y sociales derivados de la inversión extranjera en el sector de exportación. Tales ventajas giran en torno al potencial de las maquiladoras como vehículos para elevar el nivel de calificación de la fuerza de trabajo, como niveladoras de la balanza de pagos, facilitantes de la transferencia tecnológica y principalmente generadoras de oportunidades de empleo en mercados de trabajo deprimidos.

El punto al cual han sido logradas estas metas continúa siendo tema de acalorado debate. Muchos caracterizan a las maquiladoras como un nuevo instrumento de dependencia y subordinación a Estados Unidos al mismo tiempo que hacen notar numerosos abusos con respecto a la temporalidad del empleo y malas condiciones laborales que prevalecen en muchas plantas de ensamblado (Bustamente, 1976: Fernández, 1978).

Sin embargo, la expansión del programa de maquiladoras y el asombroso aumento de trabajadores empleados en ellas puede ser tomado como testi- 
monio de su éxito como extrategia económica ${ }^{4}$. Así, la expansión del Programa de Industrialización Fronteriza no se deriva de su eficacia como vehículo para un desarrollo nacional integrado sino de profundos factores determinantes que funcionan de manera independiente con respecto a las políticas delineadas por el gobierno mexicano. En muchos sentidos, tales políticas han surgido como mero intento de racionalización y legitimación de la inversión extranjera.

Existen también factores coyunturales que han precipitado tal inversión. Desde una perspectiva histórica el más importante de estos, con respecto al programa de maquiladoras, fue la terminación del programa de braceros por decisión unilateral del congreso de Estados Unidos a finales de 1964. El dramático aumento del desempleo a lo largo de la frontera mexicana ${ }^{5}$ motivó esfuerzos gubernamentales encaminados a la neutralización de los riesgos políticos que implicaban los numerosos contingentes de agricultores desempleados. También jugaron papel importante al respecto dos artículos del código de aduanas de Estados Unidos ${ }^{6}$ y los numerosos estímulos otorgados por México a la inversión extranjera en el área de exportación ${ }^{7}$.

A pesar de que el programa de industrialización de la frontera mexicana fue concebido como un paliativo para combatir el desempleo masculino generado por la terminación del programa de braceros, su resultado no previsto fue la súbita incorporación de mujeres (principalmente jóvenes y solteras) a la fuerza de trabajo industrial. Anteriormente tales mujeres no formaban parte del contingente laboral dado que no eran "empleables". Ahora $85 \%$ de la fuerza de trabajo de las maquiladoras de Ciudad Juárez es femenina; la cifra equivalente para empresas similares en todo México es de 75 \% (Ladman, 1972).

\footnotetext{
4 Parte de la explicación de tal éxito parece radicar en el hecho de que el estado mexicano ha utilizado programas de desarrollo fronterizo para generar ingresos, a través de impuestos a los inversionistas. Tales ingresos del sector público parecen haber sido utilizados para mantener estabilidad política. Por esta razón y no otra, los programas de desarrollo fronterizo parecen haber contado históricamente con apoyo del estado. El promover el empleo o elevar el nivel de adiestramiento de la fuerza de trabajo parecen ser objetivos secundarios desde este punto de vista. Véase Ugalde, 1978.

5 El desempleo llegó al 50 \% en la frontera mexicana y al comienzo de 1965. Ese mismo año Octaviano Campos Salas, Ministro de Industria y Comercio, hizo declaraciones a The Wall Street Joumal cn el sentido de que México se encontraba en situación privilegiada para competir en el mercado internacional como fuente de mano de obra barata.

6 Los artículos 806.30 y 807 del código de aduanas de Estados Unidos permiten la exportación temporal de componentes y materia prima de subsidiarios o firmas subcontratadas de firmas norteamericanas. Cuando el ensamblado ha sido realizado, los productos terminados o semi-terminados pueden re-ingresar a Estados Unidos mediante el pago moderado de un impuesto sobre valor agregado. Tal valor agregado se calcula sobte la base de los salarios pagados en el extranjero por servicios, componentes o materia prima adicional. Esto vuelve atractiva la posibilidad de trasladar operaciones de ensamblado a áreas geográficas donde los salarios son ba* jos. En la frontera mexicana los salarios equivalen a una sexta parte de los ganados por trabajadores norteamericanos por operaciones semejantes.

7 Entre estos estímulos se encuentran: a) modificaciones al párrafo III del artículo 123 del código de aduanas mexicano para permitir la entrada temporal (in bond) de maquinaria y componentes, 2) la posibilidad de adquirir propiedades en México a través de acuerdos con bancos mexicanos, 3) control total de la inversión por parte de extranjeros y, 4) a partir de 1972, la extensión de estas medidas a todo el territorio nacional.
} 
La acelerada incorporación de las mujeres a la fuerza de trabajo industrial es un rasgo que México comparte con otras áreas geográficas, especialmente en Asia, donde una similar penetración de capital transnacional en el sector de exportación manufacturera se ha llevado a efecto (Lim. L.Y.C. 1978; Southeast Asia Chronicle, 1979). Este es un punto importante por dos razones: por una parte revela la postura particular de las mujeres como portadoras de trabajo no calificado o semicalificado. Por otra parte, el mismo fenómeno permite precisar nuestra comprensión del impacto de la inversión transnacional sobre los mercados de trabajo locales.

Con respecto a la contratación de mujeres para realizar operaciones de ensamblaje el criterio convencional, compartido tanto por funcionarios públicos como por el personal administrativo de las grandes y medianas corporaciones, es que dada su paciencia, nivel de responsabilidad y alto grado de destreza manual, las mujeres están anatómica y psicológicamente capacitadas para operaciones minuciosas y monótonas. Curiosamente, tales operaciones están, por lo general, ligadas a bajos niveles salariales. Ciertamente, la mujer ha sido empleada históricamente para realizar trabajos que reportan bajos ingresos y en operaciones que son a la vez repetitivas, monótonas y alienantes. Sin embargo, el argüir que tal fenómeno se debe a rasgos biológicos - psicológicos inherentes al sexo femenino constituye una racionalización puramente ideológica. Se trata así de un intento ex-post-facto por explicar fenómenos sociales cuyas causas son más profundas y desconcertantes.

Cuando se analiza el sistema productivo como totalidad, tal descripción revela la importancia del factor "sexo" como diferenciador de la fuerza laboral cuyos miembros llevan a cabo diversas funciones y ocupan diferentes posiciones dentro de la división social del trabajo. Las mujeres son contratadas para realizar operaciones tediosas y poco gratificantes por razones de índole política y económica, no por la supuesta destreza que se deriva de su feminidad. Distintos procesos de socialización, es decir, enseñanzas arraigadas desde la infancia en hombres y mujeres estimulan el desarrollo de diferentes aspiraciones, actitudes y comportamientos que afectan su inserción en el mercado de trabajo. Debido a su corta edad y a su posición subordinada dentro de sus propias familias, las mujeres tienden a constituir una fuerza de trabajo altamente vulnerable, manipulable y dócil. El sexo como categoría social juega entonces importante papel como demarcador de alternativas laborales (Safa, 1979, mimeo sin fecha, Nash, 1975).

Como se verá a continuación, la contratación de la mujer para realizar trabajos de mínima remuneración ofrece claras ventajas desde el punto de vista empresarial. En zonas tales como la frontera mexicana, donde las diferencias raciales, étnicas, nacionales y religiosas son casi inexistentes, el sexo toma su lugar como criterio de discriminación en el mercado de trabajo. Al 
igual que con la raza, la etnicidad, la nacionalidad y la afiliación religiosa, las diferencias sexuales son utilizadas para incorporar a grupos particulares de personas a ciertos sectores de la estructura económica. Tal proceso no se realiza de manera aleatoria, sino que tiene base en la dinámica interna del sistema de producción actual.

Irónicamente, la preferencia de mujeres para realizar operaciones de ensamblaje está ligada a estereotipos y prejuicios que las vulneran directamente (Safa 1979, 1976). Así, en el caso de la frontera mexicana la combinación de juventud y sexo femenino conforma una imagen de la mujer como receptora de ingresos suplementarios y trabajadora temporal. Al mismo tiempo que la tradición patriarcal encarnada en el machismo sanciona su dependencia en el mercado de trabajo y en el ámbito familiar, juventud y sexo femenino impiden su percepción como trabajadoras legítimas con derecho a retener sus empleos por largos períodos de tiempo.

Desde el punto de vista empresarial, los mismos factores aportan condiciones óptimas para implementar políticas de empleo altamente flexibles y necesarias como vehículos de adaptación a un mercado internacional de productos manufacturados altamente competitivo. (Trajtenberg y Sjhav, 1976; NACLAS Latin America on Empire Report, 1975, 1977a, 1977b). La posibilidad de contratar una fuerza de trabajo suficientemente elástica como para ser expandida o reducida de acuerdo a repentinas fluctuaciones en la oferta y la demanda explican, en parte, la impresionante concentración de mujeres en ciertas ramas de la actividad industrial, por ejemplo, en la industria de aparatos eléctricos y electrónicos y en la del vestido. Es importante volver a enfatizar que tal concentración no puede explicarse por las peculiaridades anímicas o anatómicas de los sexos. Antes bien, debemos estudiar las condiciones estructurales objetivas que determinan la predilección de un grupo de trabajadores (hombres o mujeres) sobre otros para cierto tipo de trabajo. Conviene ahora aclarar algunos conceptos fundamentales que esclarecen el papel de la mujer dentro de los modernos procesos de producción.

\section{I.AS MUJERES Y EL EJERCITO INDUSTRIAL DE RESERVA.}

El concepto de ejército industrial de reserva está enraizado en la tradición académica del materialismo dialéctico y presupone la existencia de contingentes humanos, formados por obreros no calificados o semicalificados, que pueden ser incorporados a la fuerza de trabajo como respuesta a los requerimientos del capital en coyunturas particulares pero que también pueden ser expulsados de ella a través de diversos medios, cuando sus servicios ya no son necesarios. De acuerdo a este paradigma, la existencia de un ejército de reserva industrial aporta flexibilidad a la fuerza de trabajo, optimiza las ganancias del capital y facilita las negociaciones de los inversionistas al ser presionados por el sector obrero. 
En su formulación original este concepto se aplicó a los inmigrantes incorporados a la producción fabril de Inglaterra y Estados Unidos durante el siglo XIX (Engels, 1958). En épocas más recientes y como resultado de la creciente importancia teórica del sexo como categoría social, el mismo concepto ha sido ampliado para explicar la incorporación de la mujer al trabajo asalariado (Feber y Loury, 1976; Baudonir, Collin y Guillerm, 1978; Pearson y Elson, 1978). Muchos autores hacen notar, por ejemplo, que en ciertas épocas las mujeres son forzadas a abandonar el hogar en el que realizan tareas reproductivas, no remuneradas, para ser incorporadas al mercado de trabajo. Periódicamente, cuando sus servicios en fábricas o almacenes ya no se requieren, las mujeres deben volver al hogar. Los esquemas de referencia ideológica que fijan la función "natural" de las mujeres como madres, esposas y realizadoras de actividades domésticas facilitan este proceso. Así, desde un punto de vista ideológico, las mujeres no llegan al mercado de trabajo en forma legítima sino como empleadas emergentes que deben volver al hogar cuando la "normalidad' ha sido reestablecida.

Como en el caso de los trabajadores inmigrantes (por ejemplo los no documentados en Estados Unidos) se dice que al entrar al libre mercado de trabajo, las mujeres compiten con otros sectores de la población laboral cuyos miembros ocupan una posición similar a la de ellas. En otras palabras, el influjo de inmigrantes y/o de mujeres a la fuerza de trabajo se ve como un fenómeno que expande la oferta de mano de obra, y, como consecuencia abate los salarios y dificulta la búsqueda de mejores condiciones de trabajo para el sector obrero en general. Así, se dice que la incorporación de la mujer al mercado de trabajo diluye el impacto de la lucha de clases y retrasa el proceso de unificación del proletariado, dada la tendencia del capital a fragmentar a los trabajadores en base a sexo, nacionalidad, etnicidad, etc.

Aunque la aplicación del concepto de ejército industrial de reserva al caso de las mujeres puede aportar interesantes datos, también puede provocar peligrosos malentendidos. Por ejemplo, el concepto aludido no establece distinciones adecuadas entre la manera en que los inmigrantes (de ambos sexos) y las mujeres en particular son utilizados en la fuerza de trabajo. De manera mecánica se da por sentado que la repatriación voluntaria o forzada de inmigrantes equivale al retorno de las mujeres al hogar. Tales similitudes son superficiales y no refinan nuestra comprensión del nivel de especificidad del sexo como factor determinante de la división social del trabajo.

Desde un marco feminista, el mismo concepto presenta otras limitaciones. Por ejemplo, podría suponerse que puesto que el influjo de mujeres al mercado de trabajo acentúa la competencia, expande la oferta de mano de obra y limita la capacidad de negociación del proletariado, un curso "progresista" de acción sería el mantener a las mujeres en el hogar a toda costa impidiendo su entrada al libre mercado laboral. Aunque tal postura ha tenido 
sus defensores en círculos de la izquierda tanto en países hegemónicos como periféricos y semiperiféricos, resulta obvio que se trata de una falacia reaccionaria indefendible.

Asimismo, el concepto de ejército industrial de reserva evidencia serias limitaciones cuando se consideran las características de los mercados laborales actuales. Tal concepto presupone, de hecho; la existencia de mercados de trabajo estáticos a cuyos varios escalafones tienen acceso trabajadores con diferentes niveles de calificación. Esta presuposición guarda un curioso paralelo con concepciones similares de la economía neoclásica que también acepta la existencia de mercados nítidamente subdivididos y estables. Quizá tal concepción haya tenido alguna validez durante el siglo XIX y parte del XX pero la realidad actual bajo el capitalismo monopólico es profundamente distinta (Baudovin et al., 1978). La estructura de los mercados laborales ha sido afectada por profundos cambios en los procesos de producción. Así, el modo de inserción en el mercado de trabajo de la mayor parte de los trabajadores, responde a requerimientos concretos del capital y no a su nivel de educación o calificación.

\section{DESCALIFICACION Y FEMINIZACION DEL TRABAJO.}

Por ejemplo, varios investigadores han puesto de manifiesto que en los últimos treinta años la creciente complejidad en el diseño y funcionamiento de ciertos productos de consumo - por ejemplo en la rama eléctrica/electrónica - ha ido aparejada a la creciente fragmentación del proceso productivo de tal manera que aunque los productos terminados parecen haber sido creados por la ciencia ficción, las operaciones individuales requeridas para su ensamblado se caracterizan por una creciente simplificación. Tal paradoja ha afectado la definición misma del nivel de calificación (Baudovin et al., 1978). En pocas palabras, el mismo proceso que nos ha dado la computadora y los juegos electrónicos, ha hecho posible la "descalificación" del trabajo. Esto ha afectado tanto el trabajo fabril como las actividades en el sector de servicios, especialmente en países hegemónicos. De este modo no existen ya diferencias substantivas entre la organización del trabajo a lo largo de la línea de ensamblado y aquella que caracteriza a muchas oficinas donde la intensidad del trabajo ha aumentado al mismo tiempo que las operaciones individuales de secretarias, telefonistas, mecanógrafas y recepcionistas han sido reducidas a la repetición y la monotonía (Baudovin, et al., 1978).

Lo anterior significa que los actuales trabajadores no calificados o semicalificados son diferentes a los del pasado porque la definición misma de nivel de calificación ha sido alterada con el tiempo (Frobel, Henrichs y Kreye, 1976 y 1978). Se trata de un concepto históricamente configurado. En nuestros tiempos tal concepto depende menos de las habilidades reales de los trabajadores (nivel de educación, capital humano, adiestramiento vocacional) que de los requerimientos impuestos por los nuevos procesos productivos 
(Baudovin et al., 1978; Pearson et al., 1978). Irónicamente, al mismo tiempo que los empleos pierden nivel de calificación y otros simplemente desaparecen muchos trabajadores pueden ser portadores de mayor "capital humano".

De manera similar, la incorporación de las mujeres de zonas periféricas o semiperiféricas a la fuerza de trabajo transnacional no se debe a que estén "naturalmente" disponibles como portadoras de trabajo manual, sino a que el actual proceso de producción asegura su disponibilidad. El principal corolario de esta proposición es que las mujeres contratadas por las maquiladoras fronterizas o por plantas de ensamblado semejantes no compiten contra el proletariado no calificado varonil, simplemente porque las operaciones que aquellas han de realizar han sido, de alguna manera, diseñadas para un contingente de trabajo con características "femeninas".

Esto no significa que los varones estén intrínsecamente incapacitados para realizar trabajos manuales minuciosos (ciertamente la mayoría de los cirujanos son varones) sino que el sexo como categoría social determina la posición de hombres y mujeres en el mercado de trabajo. En efecto, el proceso antes señalado revela cierta tendencia hacia la "feminización" del proletariado internacional. Tal feminización tiene un significado más amplio de lo que parecería a primera vista ya que no sólo se refiere al crecimiento del número relativo de mujeres que trabajan, sino también al incremento del número de obreros de ambos sexos cuyos trabajos y niveles de calificación han sido redefinidos de tal manera que se aproximan al tipo de actividades tradicionalmente realizadas por las mujeres. En otras palabras, puede afirmarse que existe una reducción a nivel mundial de ocupaciones que requieren altos niveles de calificación mientras que el número de operaciones manuales simples, tediosas y mal remunerad as va en aumento.

Podría suponerse que lo anterior implica cierto nivel de intercambiabilidad de empleos entre hombres y mujeres. A pesar de las barreras ideológicas así ha sucedido en países hegemónicos como Estados Unidos, donde hay un creciente número de enfermeros, secretarios, soldadoras, operadoras de transportes públicos, etc. Sin embargo, universalmente las mujeres continúan percibiendo salarios notoriamente menores que sus contrapartes masculinos en la realización de trabajos que requieren niveles equivalentes de educación y entrenamiento. Se estima, por jemplo, que en los últimos quince años la brecha entre los salarios recibidos por hombres y mujeres en Estados Unidos ha aumentado (no decrecido). Las mujeres perciben actualmente apenas dos terceras partes de lo que perciben los hombres. (Safa, 1979).

De acuerdo con tales observaciones es posible ver nuevamente el grado al cual el sexo como categoría social y la discriminación sexual, como mecanismo de segregación laboral, operan de manera relativamente autónoma con respecto a otros factores tales como el nivel de educación. 
El proceso de feminización del proletariado y el abatimiento en los niveles de calificación pueden verse como síntomas de la difundida tendencia hacia el debilitamiento del sector obrero. La imposibilidad de obtener salarios equivalentes al alza en el costo de la vida ha motivado el que un creciente número de miembros por unidad familiar busque empleo remunerado. Tales casos muestran que cada vez con mayor frecuencia, el ingreso obtenido por un solo proveedor no es ya suficiente para mantener niveles adecuados de subsistencia de una célula familiar (Safa, 1979). Las mujeres son las primeras en buscar los mal llamados empleos "suplementarios". A lo largo de la frontera mexicana la enorme difusión de este fenómeno se encuentra ligada de manera precisa a la exclusión de los hombres de empleos adecuadamente remunerados.

En suma, desde esta perspectiva las mujeres no forman un ejército de reserva industrial a no ser que este término se aplique en relación a ellas mismas esto es, en relación a otras mujeres con características similares y, por lo tanto, empleables en semejantes trabajos. Por tanto no parece ser realista el suponer que los trabajos manuales, mal remunerados y temporales que se realizan en muchas maquiladoras serían realizados por los miembros de la población varonil si no les fueran "arrebatados" por las mujeres (Baudovin et al. 1978).

La fragmentación de los procesos productivos y la consecuente descalificación del trabajo han producido una reducción del tiempo necesario para adiestrar a la fuerza de trabajo. Esto tiene la enorme ventaja de reducir los costos fijos de la producción y diversificar riesgos políticos. Al mismo tiempo, el relativamente fácil adiestramiento, al igual que los cada vez más cortos períodos necesarios para entrenar personal, permiten el acceso a crecientes grupos de trabajadores cuyos miembros son verdaderamente prescindibles dependiendo de las condiciones del mercado.

Esto brinda al capital mayor fluidez a través de la transferencia de etapas productivas a diversos puntos geográficos. Es en estos factores donde debemos buscar la explicación de la expansión del programa de maquiladoras. Al mismo tiempo que la sofisticación tecnológica y de diseño tiende a centralizarse en los países hegemónicos, las operaciones manuales tediosas y mal remuneradas pueden ser exportadas a zonas periféricas o semiperiféricas como la frontera mexicana. Así, actualmente el crecimiento de la brecha entre trabajo "manual" y trabajo "intelectual" implica tanto diferencias de clase como dispersión geográfica. Este es un aspecto fundamental en la división contemporánea del trabajo a escala mundial. 


\section{RAMA MANUFACTURERA, MERCADO INTERNACIONAL Y POLITICAS DE CONTRATACION.}

¿Cuál es la situación de las compañías manufactureras que operan bajo el programa de maquiladoras dentro del marco delineado anteriormente en el contexto del capitalismo global?

Como se ha señalado anteriormente, dos ramas de producción, la eléctrica/electrónica y la del vestido, dominan la actividad productiva a lo largo de la frontera México-Estados Unidos. Tal preponderancia indica que las ventajas derivadas de la transferencia de operaciones de ensamblaje a países periféricos y semiperiféricos no son idénticas para todos los ramos industriales. Numerosas restricciones políticas y legislativas, al igual que ciertas barreras arancelarias, evitan que muchos procesos manufactureros sean parcial o totalmente exportados. Este es el caso, por ejemplo, de la industria pesada que continua concentrada actualmente en países hegemónicos como Estados Unidos.

Las llamadas "industrias ligeras" presentan características muy diferentes. Tomemos el ejemplo de la industria eléctrica/electrónica y la del vestido. En ambos casos el factor decisivo que explica su comportamiento es la posición que guardan en el contexto del mercado internacional. Ambas industrias se caracterizan por su alta capacidad de absorción de mano de obra; ambas requieren bajos niveles de inversión para iniciar operaciones; ambas están sujetas a súbitas fluctuaciones de la oferta y la demanda y ambas sufren los estragos de la obsolescencia constante. En el caso de la industria del vestido, esta última característica se debe principalmente al carácter estacional de la moda y a los consiguientes cambios de estilo. En la rama eléctrica/electrónica los factores determinantes son la innovación tecnológica y las cada vez más complejas alteraciones de diseño. La invención del circuito integrado y la partícula de silicón han transformado esta industria radicalmente en la última década. La competencia por obtener información técnica y de diseño en esta industria alcanza niveles de ferocidad casi indescriptibles (Siegel, 1981).

A pesar de que existen similitudes estructurales compartidas por las industrias eléctrica/electrónica y la del vestido, también existen diferencias importantes. Hay, por ejemplo, mayor tendencia hacia la centralización de la producción en la rama eléctrica/electrónica que en la manufactura de prendas de vestir; seis compañías electrónicas realizan más del $92 \%$ del total de las ventas de computadoras en Estados Unidos y una sola de ellas, la IBM, controló este renglón con una participación del 65.5\% \% del mercado en 1975 (Business Week, 1976). Aún así, la centralización no ha alcanzado el nivel monopólico que caracteriza a otras ramas industriales, por ejemplo, la automotriz. Esto se hace evidente cuando se observa que 6,000 compañías aún 
compiten en la manufactura de aparatos eléctricos y electrónicos; aproximadamente la mitad de ellas producen partes para otras compañías del mismo ramo (Electronic News, 1977).

Aunque existen algunos gigantes en el ramo de la electrónica, no existe ninguno comparable en la industria del vestido. En ésta las ventas de las mayores compañías representan solamente el $5 \%$ del total de las ventas totales de la industria (Electronic News, 1977). Finalmente, la inversión de capital en tecnología e infraestructura es mayor (incluyendo la proporción de la inversión de capital por obrero) en la rama eléctrica/electrónica que en la del vestido.

Al considerar estos factores queda claro que mientras ambos tipos de producción son altamente competitivos, por diversas razones, en el ámbito internacional, la industria eléctrica/electrónica posee rasgos monopólicos ausentes en la industria de manufactura de prendas de vestir. Sin lugar a dudas, la vulnerabilidad compartida por estas industrias en el mercado mundial hace necesario constantes intentos por reducir los costos de producción al mínimo. En parte esto explica la transferencia de operaciones intensivas, como el ensamblado, a zonas geográficas periféricas y semiperiféricas.

Sin embargo, son las diferencias que se hacen obvias tras de la comparación de ambos tipos de actividades manufactureras las que explican las variaciones en las políticas de contratación de personal en los dos ramos. Tales prácticas de contratación también dependen del tipo de relación que existe entre las firmas principales y sus compañías afiliadas en el exterior. Por ejemplo, las compañías eléctricas/electrónicas que operan a lo largo de la frontera mexicana establecen casi siempre subsidiarias, mientras la mayoría de las compañías de manufactura del vestido utilizan los servicios de una o varias plantas subcontratadas. En primer ejemplo asegura cierta estabilidad vinculada a mayores niveles de inversión de capital. En ese caso las transacciones internas a las compañías facilitan enormemente las funciones administrativas y la circulación de partes y de maquinaria (Newton y Balli, 1979; Najar, 1977; Martin y Tallock, 1977).

Así, el eficaz control administrativo interno de las corporaciones y sus subsidiarias en el exterior, protege a la firma de fluctuaciones en la oferta y la demanda, al menos durante períodos normales de actividad económica. En Ciudad Juárez, compañías como la RCA Componentes de Televisión, Electro Componentes de México (General Electric) y Conductores y Componentes Eléctricos (General Motors) ejemplifican este postulado. No sólo se caracterizan estas maquiladoras por sus modernos edificios ubicados en parques industriales de reciente construcción sino que también han comprometi- 
do parte de sus inversiones en el adiestramiento de personal de nivel medio, en la capacitación de sus obreros y en la promoción del programa de maquiladoras. Por estas mismas razones ofrecen trabajos relativamente estables y algunas "compensaciones" adicionales.

Estos rasgos dan como resultado políticas de contratación altamente selectivas. No es fácil conseguir trabajo en este tipo de fábricas; las obreras deben contar con un nivel de instrucción relativamente alto (se requiere no menos de seis años de instrucción formal y no son raros los casos de mujeres que trabajan en las maquiladoras con años adicionales de estudio y/o entrenamiento vocacional). La mayoría deben ser jóvenes (el rango de edad preferido por los gerentes de personal va de los 17 a los 25 años), solteras y sin hijos. Muchas maquiladoras también exigen la disponibilidad de las obreras para varios turnos (caracter ística que impide la participación de mujeres con responsabilidades domésticas permanentes) y que puedan comprobar un período de residencia mínimo en Ciudad Juárez. Las compañías frecuentemente realizan investigaciones para confirmar la veracidad de las declaraciones de sus solicitantes, mientras que otras sólo aceptan trabajadoras nuevas a través de recomendaciones directas de su personal más antiguo.

Antes de obtener un trabajo como operadora directa de producción en una maquiladora eléctrica/electrónica, una mujer tiene que pasar una o varias pruebas de destreza manual así como un examen médico, cuyo propósito principal es el prevenir que mujeres embarazadas se integren a la fuerza de trabajo de las maquiladoras. Como puede verse, los numerosos requisitos listados arriba están fuera de proporción con el tipo de operaciones mecánicas y tediosas realizadas en las fábricas y con los bajos salarios percibidos por las obreras. En parte, estas políticas selectivas de contratación pueden ser implementadas debido a la abundancia de mujeres en busca de trabajo, en un medio en el que el subempleo y el desempleo combinados alcanzan $30 \%$. También debe recordarse que el alto nivel de discriminación en las políticas de contratación asegura la posibilidad de ejercer fuerte control sobre las obreras; sexo y juventud producen una fuerza de trabajo muy dócil.

Así, las corporaciones transnacionales que operan en zonas periféricas o semiperiféricas a través de subsidiarias propias tienden a comportarse de manera similar a las industrias monopólicas de los países hegemónicos. Por otra parte, y desde la perspectiva de las mismas obreras, los trabajos ofrecidos por estas compañías son codiciables. Además de la atención médica provista a través de su afiliación al Instituto Mexicano del Seguro Social ${ }^{8}$, también ofrecen ingreso regular, ganado mediante el trabajo en modernas instalaciones. Muchas de estas compañías ofrecen programas de ahorros y préstamos así co-

8Por la ley, todas las maquiladoras deben afiliar a sus empleadas al Instituto Mexicano del Segruo Social y pagar el salario mínimo sancionado por la Comisión Federal de los Salarios Mínimos. 
mo aguinaldos periódicos y actividades deportivas como incentivos adicionales. Aún el hecho de que algunas de estas maquiladoras tengan comedores o cafeterías que evitan a las obreras la necesidad de comprar comida de vendedores ambulantes, es visto como un punto atractivo.

A pesar de que estos sean vistos como beneficios modestos desde el punto de vista de los trabajadores sindicalizados de países hegemónicos,siguen siendo excepcionales en las zonas periféricas y semiperiféricas. Así, las corporaciones que pueden ofrecer estos incentivos a sus obreros también están en posición que les permite contratar individuos "privilegiados" en términos de educación, estado civil y edad.

La subcontratación ofrece un perfil muy diferente. En este caso, que caracteriza a las maquiladoras de ropa, los acuerdos entre las empresas matrices y sus asociadas en el extranjero son generalmente débiles. Se trata, con frecuencia, de pequeñas empresas mexicanas cuyos accionistas han buscado las ventajas de los incentivos otorgados por el gobierno a las corporaciones multinacionales. Para lograr ésto, muchos empresarios han decidio exportar parte de su producción bajo las estipulaciones del programa de maquiladoras, mientras el resto de la misma es dirigido al mercado nacional. Otros han creado compañías nuevas que dependen por completo de la demanda de empresas extranjeras. En estos casos la gerencia no sólo debe responsabilizarse de la coordinación de la fuerza de trabajo sino también de la adquisición de contratos. Una cancelación repentina puede llevar a estas empresas a la bancarrota $y$, en el pasado, han forzado su clausura ${ }^{9}$. Por esta razón el oportunismo económico es rasgo común entre estas compañías; su vulnerabilidad depende en parte de su posición en el mercado internacional y de sus propias limitaciones a las corporaciones con las que se han asociado.

La desafortunada consecuencia de ésto ha sido la proliferación de plantas minúsculas en las que prevalecen pésimas condiciones de trabajo. De ahí que el empleo en este ramo sea inestable, las instalaciones deficientes, el equipo anticuado, los requisitos laborales arbitrarios y comparativamente más estrictos, las exigencias sobre la productividad excesivas y los abusos no poco frecuentes. Los altos índices de rotación de personal indican la necesidad de mantener una fuerza de trabajo extremadamente elástica. En pocas palabras, estas industrias representan al sector competititvo por excelencia. No obstante que firmas como Sears Roebuck, el grupo Warnaco y Johnson y Johnson están asociadas por corporaciones de mediano o pequeño tamaño que tienen importancia regional y no nacional. Entre estas están Billy the Kid, Pionner, Zenith Shirt, etc.

9 Un caso dramático de esto ocurrió durante la recesión de 1975 que afectó a Estados Unidos. Miles de trabajadoras en Ciudad Juárez fueron despedidas como resultado de la clausura de muchas maquiladoras o las bajas en la producción. 
En conjunción con los niveles de inversión y una posición precaria en el mercado internacional, estas maquiladoras se distinguen por prácticas de contratación que difieren marcadamente de aquellas que prevalecen en la industria eléctrica/electrónica. Para ser breves, las fábricas de manufactura del vestido tienden a contratar obreras cuya posición en el mercado de trabajo local es mucho más débil que la de aquellas contratadas por las subsidiariás propias de la industria eléctrica/electrónica (Pearson y Elson, 1978).

Entre estas obreras hay un gran número de mujeres mayores (la edad promedio es de 26 años en contraste con 20 años para las obreras de rama eléctrica/electrónica). Debido a este factor tales mujeres encuentran difícil conseguir trabajo en otra parte. Muchas son madres solteras que representan el único medio de sustento para sus hijos; muchas han buscado trabajo tras haber sido abandonadas por sus maridos o haber perdido el apoyo económico de los hombres de su familia.

Varios estudios indican que la ausencia de apoyo económico masculino es un factor decisivo que acelera el ingreso de las mujeres a la fuerza de trabajo asalariado (Parnes, 1970). Si bien ésto es cierto acerca de muchas mujeres que trabajan en diversas clases de maquiladoras, es particularmente válido para aquellas que trabajan en la industria del vestido. Sin lugar a dudas, los datos que arroja la investigación demuestran que una de cada tres mujeres empleadas por el sector manufacturero de prendas de vestir son cabezas de familia10. El perfil general de estas obreras también indica que tienen un promedio de instrucción menor que el de las operadoras directas de producción del sector eléctrico/electrónico. Debido a su extrema necesidad económica, estas mujeres no tienen otra alternativa que la de aceptar condiciones desfavcrables de trabajo y las altas cuotas de producción que prevalecen en la industria del vestido. La posibilidad de ganar el salario mínimo - aunque sea por períodos cortos-y el ser incorporadas al Instituto Mexicano del Seguro Social, hacen que estas fábricas sean mejores alternativas que el trabajo doméstico, el trabajo como empleadas en el sector de servicios, o en la llamada "economía informal".

En breve, el punto a enfatizar aquí es que la presencia de dos tipos de actividad industrial en Ciudad Juárez efectúa varias subdivisiones dentro del mercado de trabajo social. Por una parte, al contratar principalmente mujeres para operaciones de ensamblaje no calificadas o semicalificadas, las corporaciones transnacionales establecen una subdivisión del mercado de trabajo en base a las segregación sexual, lo cual afecta profundamente las posibilidades de empleo tanto para hombres como para mujeres. Por otra parte, las dife-

\footnotetext{
${ }^{10} \mathrm{Los}$ datos empíricos contenidos en estas páginas se basan en los resultados preliminares arrojados por una muestra aleatoria recabada por la autora entre 1978 y 1979 . La muestra está formada por 510 trabajadoras en 14 plantas maquiladoras a quienes se entrevistó con respecto a puntos sobre antecedentes migratorios, distribución de ingreso, historia laboral y composición familiar.
} 
rencias en la clase de actividad manufacturera y en la relación entre compañías matrices y sus asociados en el exterior dan como resultado estrategias variables de adaptación que involucran diferentes prácticas de contratación. Estas, a su vez, efectúan subdivisiones aún más sutiles dentro de una fuerza de trabajo predominantemente femenina.

El postulado teórico central que se desprende de estas consideraciones es que las diferencias que caracterizan a los varios grupos que integran una fuerza de trabajo específica reflejan diferencias esenciales en el proceso mismo de producción. De ahí que sea necesario prestar atención a los acuerdos institucionales que controlan la producción (ésto es, a las relaciones sociales de producción) en cualquier intento por explicar la composición de la clase obrera (Edwars, Reick, Gordon, eds., 1975).

\section{CARACTERISTICAS INDIVIDUALES Y ORGANIZACION FAMILIAR DE LAS OBRERAS EMPLEADAS EN LA INDUSTRIA MAQUILADORA DE CIUDAD JUAREZ}

Como queda planteado anteriormente varios factores característicos de la presente etapa del desarrollo capitalista han contribuido a la creciente fragmentación de los procesos productivos, a la redefinición de niveles de calificación y a la fluidez de inversiones de capital a nivel mundial. Estos aspectos se han reflejado a su vez, en la tendencia hacia la "feminización" de crecientes contingentes obreros. Pero si bien los requerimientos de la acumulación y reproducción de capital determinan la demanda de ciertos tipos de trabajo (del cual las mujeres pueden ser las portadoras ideales), esto no proporciona información alguna acerca de los factores que determinan la oferta de mano de obra. En términos rigurosos, lo que importa desde el punto de vista de la mentalidad capitalista no es que los obreros sean hombres o mujeres, sino que éstos puedan ser utilizados para redituar ganancias y productividad máxima bajo las circunstancias políticas menos comprometedoras.

¿Por qué entonces se convierten las mujeres, cada vez con mayor frecuencia, en las portadoras del trabajo no calificado y semicalificado? Contrariamente a lo que pudiera parecer a piimera vista, la respuesta a esta pregunta no es obvia sino que requiere una profunda investigación de la unid ad familiar. Es decir, sólo a través del análisis de la organización y estructura familiar es posible ir más allá del análisis superficial ligado a conceptos tales como "ejército industrial de reserva" y "mano de obra barata" (Fernández, 1980a).

Este es un aspccto difícil de abordar porque con frecuencia se supone que la forma que adoptan las unidades reproductoras de escala menor, tales como la familia, son resultado automático de las necesidades del capital. Así, se ha visto a la familia como instrumento para la realización de actividades sociales reproductivas que subsidian la acumulación del capital en base a 
la subordinación femenina, como unidad de consumo necesaria para expandir mercados, o como vehículo de transmisión y perpetuación ideológica.

En general este puede ser un postulado válido, pero cuando se toma literalmente produce interpretaciones superficiales de fenómenos complejos. Algunos autores, por ejemplo, han investigado el papel jugado por la familia como bastión de resistencia contra las imposiciones del capital (Caufield, 1974; Deere, Humphries y León de Leal, 1978; Scott y Scott, 1978; Kuznets, 1976). Otros han enfatizado la autonomía relativa de la organización familiar en relación con las demandas de capital (Largia y Dumoulin, 1975). En general, debiera reconocerse que existe una considerable variedad en la organización interna de los hogares aún cuando compartan antecedentes de clase similares; los hogares a los que pertenecen las obreras de las maquiladoras de Ciudad Juárez no son la excepción a esta regla.

Un breve bosquejo de las características personales y familiares de las trabajadoras de la industria maquiladora puede contribuir a esclarecer este punto. Comúnmente se piensa en Ciudad Juárez que las maquiladoras contratan principalmente a inmigrantes. Esta es una impresión parcialmente válida ya que el $70 \%$ de las mujeres contratadas por la industria maquiladora de Ciudad Juárez nacieron fuera de la ciudad. Los focos principales de migración se localizaron en tres estados mexicanos norteños: Chihuahua, Coahuila y Durango, mientras que sólo un porcentaje mínimo de inmigrantes $(30 \%)$ nacieron en estados mexicanos del cen tro o sur del país.

Un número notable de trabajadoras de maquila $(15 \%)$ provienen de la zona circunvecina a Santa Bárbara, Hidalgo del Parral y San Francisco del Oro, Chihuahua. Se requiere una investigación de la economía política de esta área para explicar la concentración de migrantes que ahora laboran en las maquiladoras juarenses. Sin embargo, debe recordarse que tal área fue por mucho tiempo foco de actividad minera promovida por la gran empresa norteamericana ASARCO. Asimismo, experimentó la presencia de capital intensivo foráneo en el sector agrícola a través de firmas como la John Deere. Las dislocaciones generadas por la intervención de capital extranjero y su abrupta disminución años después, en ausencia de políticas de desarrollo adecuadas, parece haber generado dislocaciones sociales y flujos migratorios. Podría tratarse así, de un caso en el cual la inversión transnacional en actividades económicas tradicionales como la minería y la agricultura produjo, al pasar de los años, un contingente de trabajadores desplazados migrantes cuyas hijas ahora son empleadas por las modernas industrias ligeras: las maquiladoras.

Aunque la mayor parte de las obreras de ensamblaje tienen claros antecedentes migratorios, sólo el $8 \%$ proviene del medio rural. Esto indica la existencia de flujos migratorios urbanos (y no migración rural-urbana) en el caso de las trabajadoras de maquila. Más importante aún es el hecho de 
que a pesar de que la mayoría de las obreras de maquila de esta ciudad son inmigrantes, su promedio de residencia en Ciudad Juárez es de 14 años. Lo anterior denota el interesante hecho de que estas jóvenes llegaron a la ciudad a edad muy temprana y como dependientes de sus familiares, principalmente padres o hermanos mayores. Un promedio de cinco familiares llegó a Ciudad Juárez por cada obrera migrante. Sólo un pequeño número de mujeres abandonó su pueblo natal independientemente y con el explícito objetivo de buscar trabajo en Juárez. Aún menos viven actualmente solas o con amistades del mismo grupo de edad. La gran mayoría vive con su familia. En resumen, la migración familiar está estrechamente vinculada al pasado de las jóvenes actualmente empleadas en la industria maquiladora de Ciudad Juárez. Asimismo, con base en su lugar de nacimiento y debido al largo período de residencia en Ciudad Juárez, estas mujeres deben considerarse como una población urbana y no rural.

El extenso período de residencia en Ciudad Juárez está relacionado de manera importante con factores tales como el nivel de instrucción y el tipo de experiencias laborales de las trabajadoras. Obviamente la mayoría de éstas, tanto immigrantes como no inmigrantes, han asistido a la escuela en Ciudad Juárez y tienen un nivel de escolaridad más elevado que el promedio en México. Mientras que el promedio de escolaridad del trabajador mexicano es de 3.8 años, la mayoría de las obreras de maquiladora han completado cuando menos 6 años de instrucción (Bayer, 1979). Muchas han tomado cursos en academias comerciales, tal como lo manifiesta el breve relato biográfico al inicio de este artículo. Algunas han estudiado para ser enfermeras, auxiliares de enfermería, secretarias, técnicas de computación, estilistas o costureras. Debido a su relativamente alto nivel de educación formal y a su familiaridad con el medio urbano, estas trabajadoras pueden ser fácilmente entrenadas en cortos períodos de tiempo.

Muchos gerentes de maquiladora señalan que éstas son características valiosas ya que difieren considerablemente de las de la población rural. Al decir de los mismos, al inmigrante rural generalmente se le dificulta aceptar la estricta disciplina e inflexibles exigencias de producción que prevalecen en las maquiladoras. Desde luego, ésto no quiere decir que todas las obreras de maquiladoras tienen el mismo nivel de educación. Existen diferencias importantes ya que como se dijo anteriormente, los criterios de contratación varían de fábrica en fábrica. Existen, por ejemplo, notales diferencias en los niveles de escolaridad cuando se compara a las obreras de la industria eléctrica/ electrónica con la del vestido.

En parte debido a su juventud, la mayoría de las obreras de maquila cuentan con experiencia laboral limitada. Especialmente en la rama eléctrica/electrónica en la que la edad promedio de las obreras es de 20 años, la mayoría (aproximadamente el $60 \%$ ) no han desempeñado trabajos anteriores al que actualmente tienen. Por el contrario, en la rama de manufactura 
de prendas de vestir, en la que la edad promedio de las trabajadoras es de 26 años, menos del $30 \%$ de las entrevistadas no habían desempeñado otra clase de trabajos.

En general, se identificaron dos experiencias laborales (a veces sobrepuestas) entre las trabajadoras con experiencia laboral anterior a su empleo en la industria maquiladora. El primer grupo lo forman mujeres que han tenido empleo en el sector de servicios como dependientas de mostrador, cajeras, vendedoras, estilistas, auxiliares de oficina y secretarias. El segundo grupo está integrado por aquellas mujeres cuya única experiencia de trabajo previa fue como empleadas domésticas en Ciudad Juárez o en El Paso, Texas. Entre las integrantes de este último subgrupo casi todas habían trabajado como migrantes no documentadas, habiendo cruzado la frontera en repetidas ocasiones en forma ilegal.

\section{MAQUILADORAS Y MIGRACION ILEGAL}

Conviene ahora hacer un breve paréntesis para plantear de manera detallada las condiciones bajo las cuales las mujeres inmigran ilegalmente a Estados Unidos. Sólo el caso de las obreras de maquiladoras será tratado por el momento.

Una premisa fundamental en el estudio de la migración debiera ser el dejar establecido que el factor sexo determina el grado de movilidad geográfica accesible a hombres y a mujeres. Los hombres guardan cierta autonomía relativa con respecto a la unidad familiar y especialmente con respecto a las funciones domésticas y reproductivas que son vistas como responsabilidad primordialmente femenina. Es, por tanto, más fácil para los varones el enfrentar los riesgos ligados a la inmigración ilegal o indocumentada. Varios autores hacen notar que los trabajadores no documentados generalmente emigran solos y tienden a permanecer largos períodos de tiempo alejados de sus familias ${ }^{11}$. Las mujeres, por el contrario, deben cruzar la frontera diariamente en ambas direcciones debiendo buscar trabajo como empleadas domésticas en ciudades fronterizas de Estados Unidos. Tales trabajadoras por lo general deben volver a México todas las noches o al menos cada fin de semana para cuidar de sus hijos o para visitar a sus familiares.

Ciertamente, el temor y ansiedad que infunde el Servicio de Inmigración y Naturalización de Estados Unidos es compartido por hombres y mujeres. Sin embargo, las experiencias de ambos con respecto a la inmigración es marcadamente distinta. Se espera que los varones, socializados para desempeñarse como "proveedores," envíen dinero y/o regalos a sus familias en México y que las visiten ocasionalmente. En cambio, las mujeres tienen responsabilidad directa y total del cuidado diario de sus hijos y sus hogares. Cuando tienen

11 Para una bibliografía extensa y estado de la investigación actual sobre migración, véase Cornelius, 1979. 
que trabajar por un salario, deben también regresar frecuentemente para hacerse cargo de lo que se consideran las responsabilidades naturales del sexo femenino. Así, la muy difundida noción encarnada en refranes como "el hombre para el trabajo y la mujer para su casa", limita la posibilidad de movilidad femenina, a la vez que grava su existencia con el doble yugo del trabajo asalariado y el hogareño.

Así, no resulta sorprendente el que la mayor parte de las mujeres indocumentadas que emigran solas a Estados Unidos para permanecer largas temporadas en ese país sean solteras y tengan uno o ningún hijo. Tales mujeres pueden internarse hacia sitios lejanos en busca de mejores trabajos. Su estado civil y su limitada responsabilidad familiar hacen que su experiencia y su gama de alternativas sea semejante a aquella de sus contrapartes masculinos.

El caso de las mujeres que tienen menores a su cuidado es distinto. Tales mujeres se arriesgan a ser detenidas y deportadas 12 con mayor frecuencia porque cruzan la frontera constantemente. Irónicamente, es precisamente la necesidad de mantener a sus hijos las que las lleva a buscar trabajo en Estados Unidos. Cuando se consideran los riesgos involucrados en la migración ilegal, resulta claro que el empleo en una maquiladora es una mejor alternativa para estas mujeres aunque signifique cierto deterioro de su ingreso neto en comparación con los salarios derivados del trabajo doméstico en ciudades fronterizas de Estados Unidos. De hecho, tal deterioro se compensa por el acceso a servicios médicos como afiliadas al Instituto Mexicano del Seguro Social. Tal afiliación constituye un poderoso incentivo para el empleo desde el punto de vista de las trabajadoras. En cierto sentido,el paso del trabajo doméstico ilegal al empleo fabril en territorio nacional representa, desde esta perspectiva, un paso ascendente en la jerarquía ocupacional.

Sin embargo, la situación es distinta para las obreras con anterior empleo como secretarias, recepcionistas, estilistas, enfermeras, etc. Su experiencia representa una singular transferencia de trabajo del sector medio de servicios al trabajo fabril. Esta transferencia contradice lo que ha sido considerado como la tenencia "normal" en la movilidad ocupacional dentro de la perspectiva teórica de la "modernización"13. Según esta perspectiva, el curso natural de acontecimientos consiste en la migración rural urbana y el paso de trabajo agrícola al fabril, seguido por el empleo en posiciones medias en el sector de servicios y oficinas. ¿A qué se debe que ésto no suceda en Ciudad Juárez?

\footnotetext{
12 Muchas sirvientas ilegales que trabajan en ciudades fronterizas de Estados Unidos usan una visa emitida por el Servicio de Inmigración y Naturalización a ciudadanos mexicanos. Su objetivo es estimular el consumo de los mexicanos en el país vecino. Sin embargo, explícitamente limitan la permanencia de sus portadores a 72 horas y prohiben el trabajo asalariado.

13 Para una crítica de la perspectiva de la modernización véase Portes, 1981. Véase también Schmink, 1979.
} 
De nuevo, la explicación de este fenómeno se puede encontrar en la estructura particular del mercado de trabajo juarense. A pesar de que el sector de servicios predomina a lo largo de la frontera mexicana (Urquidi y Méndez, 1978), la mayoría de los empleos que se encuentran en él son inestables, mal remunerados y carentes de beneficios adecuados. Esto es cierto aún con respecto a aquellos renglones dotados de mayor prestigio que el trabajo en fábrica. Ciertamente, la mayor parte de las recepcionistas, vendedoras de mostrador y secretarias de Ciudad Juárez ganan menos que las obreras de maquiladora. Los empleos de mayor prestigio y mejor pagados son únicamente accesibles a personas con alto nivel de adiestramiento y/o que hablan correctamente el inglés.

Así, muchos empleos en el sector de servicios y el trabajo doméstico asalariado son casi intercambiables. A nivel local, existe común acuerdo en que el trabajo de maquiladoras constituye la mejor alternativa de empleo en Ciudad Juárez. Esta es una opinión sorprendente cuando se recuerda que las obreras de maquila ganan aproximadamente 60 centavos de dólar por hora, y sostienen agotadores ritmos de trabajo, al mismo tiempo que laboran casi continuamente cuarenta y ocho horas a la semana; que el empleo de maquiladoras sea una alternativa deseable dentro del sector obrero revela más que otra cosa el grado limitado de alternativas que ofrece el mercado de trabajo juarense.

Existe un corolario importante a las consideraciones hechas con anterioridad. Si fuera cierto que la mayoría de las mujeres que trabajan en las maquiladoras de Ciudad Juárez trabajan principalmente como individuos, ésto es, para satisfacer necesidades personales o para suplementar el ingreso familiar, es probable que no optarán por un trabajo proletario. Aún menos remunerativos, existen trabajos en Ciudad Juárez que no implican las rigurosas exigencias e inflexibles horarios de las maquiladoras. La realidad, sin embargo, es que estas mujeres se han integrado a la fuerza de trabajo como miembros de familias para cuya subsistencia sus ingresos son vitales.

En parte, ésto se debe al tamaño y composición de sus unidades familiares. Esta autora encontró, por ejemplo, que mientras que el número promedio de miembros por familia en Ciudad Juárez es en general de 5.3, el número equivalente en los hogares de las obreras de maquiladora es de 7 (University of Texas, 1978). Cuando se considera que Ciudad Juárez es una ciudad en la que el $49 \%$ de la población tiene 14 años o menos, se hace obvio que la necesidad de responder a las necesidades infantiles - ya sean hijos o hermanoses un factor que contribuye a precipitar la búsqueda de trabajo por parte de las mujeres.

No obstante, más grave aún es la escasez de alternativas reales de empleo para los hombres de las familias de las obreras de maquiladoras. La importancia de esta observación puede apreciarse cuando se subraya que la mayoría 
de los hombres que cohabitan en tales familias están desempleados o subempleados. Entre aquellos que tienen trabajo, las ocupaciones predominantes, en orden de importancia, son: albañil, empleado en comercio menor, jornalero y vendedor ambulante (Fernández, 1980b). De ahí que exista una convergencia entre las condiciones del mercado de trabajo y las necesidades familiares, la cual facilita la utilización de mujeres como mano de obra barata para las maquiladoras. El resultado de ésto ha sido rápida transformación de las mujeres en proveedoras principales de ingreso regular y estable (aunque mínimo) para sus familias.

Los beneficios derivados de esta estrategia se ven incrementados cuando varias mujeres pertenecientes a una misma familia son capaces de obtener trabajo en las maquiladoras. La abundancia de mujeres en busca de trabajo presupone, por lo tanto, la imposibilidad varonil para obtener trabajos decorosos. Así, en un país en el que para bien o para mal, las mujeres aspiran y son motivadas a ser madres y/o amas de casa, el trabajo de fábrica femenino no significa una expansión de sus alternativas familiares o individuales; todo lo contrario, puede significar un aumento en el grado de explotación al que se encuentran expuestas.

\section{LAS MAQUILADORAS Y EL CAMBIO CULTURAL}

¿Cómo afecta la participación de la mujer en el trabajo asalariado a ciertos patrones culturales tales como la estructura y organización familiar? ¿Acaso el incremento del trabajo industrial femenino en lugares como Ciudad Juárez traerá consigo una mejoría en la posición política y económica de la mujer dentro y fuera de la familia?

Si hemos de creer a la opinión expresada por los medio de comunicación de Ciudad Juárez, el programa de maquiladoras ha llevado a cabo una especie de emancipación femenina al brindar a las mujeres la oportunidad de obtener su propio ingreso. Se le ha dado importancia al hecho de que ahora las mujeres pueden gastar en ropa, cosméticos, joyería y diversiones. Esta aseveración parece estar sustentada por la proliferación de almacenes de ropa, discotecas y bares favorecidos por las obreras de maquila.

La propaganda exhorta a tales mujeres a adquirir multitud de bienes y servicios, muchos de los cuales han sido generados como parte del Programa Nacional Fronterizo (PRONAF). Solo se necesita caminar por las transitadas calles del cen tro de Juárez para percatarse del grado al cual las industrias maquiladoras han transformado el semblante comercial de la ciudad. Muchos almacenes y tiendas anuncian con entusiasmo su deseo de facilitar el cambio de cheques de pago provenientes de las maquiladoras y el hacer extensivos a sus obreras los beneficios del crédito y los planes de apartado. La preferencia de las trabajadoras por los cosméticos Avon y por la joyería de fantasía Stanley, han adquirido una reputación legendaria en este medio. 
Durante los días de pago muchos vendedores ambulantes y carros de alquiler fluyen a sitios próximos a las fábricas con la esperanza de obtener una tajada de la supuesta riqueza disfrutada por las obrerac de maquila. Una imagen común en esos días está formada por grupos de hombres que esperan afuera de las plantas, la salida de las trabajadoras; algunos de estos hombres son familiares que esperan para escoltar a sus hijas o esposas a sus hogares reduciendo así la posibilidad de asalto o robo. Pero muchos otros son oportunistas que esperan obtener alguna invitación a los bares o a los salones de baile; éstos son diestros en las artes de la seducción.

Debido a que en muchos casos hijas y esposas ganan más que los maridos o los padres, algunos creen que el trabajo femenino en maquiladora ha producido una particular inversión de roles sexuales que altera los patrones tradicionales de autorid ad en la familia. Se supone, por ejemplo, que al invertir parte de su tiempo en el trabajo fabril, las mujeres forzan a los hombres a asumir mayor responsabilidad en los quehaceres domésticos (principalmente si están desempleados o subempleados), con efectos perniciosos sobre su sentido de la hombría. Donald Baerressen señala, por ejemplo que "algunas familias son mantenidas casi por completo por el ingreso de. . . una hija. .. Seguramente el ego de los padres y futuros novios ha de sufrir alguna devaluación por este dramático cambio en el poder económico de estas jóvenes mujeres" (Baerressen, 1971).

La superficialidad con la cual este autor reduce a la frase anterior un problema complejo, no es poco común por desgracia. A este respecto, dos perspectivas opuestas pero interrelacionadas han obtenido prominencia. Por una parte están aquellos que alaban el trabajo industrial femenino como instrumento para fortalecer la autonomía de la mujer y su poder de negociación tanto en el hogar como en el mercado de trabajo. Estos ven con buenos ojos los procesos de industrialización porque creen que mediante ellos se aceleran los procesos de modernización. La participación de las mujeres en la fuerza de trabajo es vista como una fuerza positiva que facilita la eliminación de patrones culturales arcaicos. Muchos promotores del programa de maquiladoras se adhieren a este punto de vista. Por tanto, ven a las corporaciones transnacionales como elementos progresistas y frecuentemente expresan desprecio por la cultura nacional. Resulta interesante que aquellos que comparten esta perspectiva también alaban las virtudes de las maquiladoras como generadoras de disciplina, puntualidad y eficiencia entre los miembros de una fuerza de trabajo antes desorganizada y apática. En particular, señalan que las mujeres se han beneficiado a través del trabajo fabril, siendo que anteriormente sólo podían escoger entre el insignificante empleo comercial, el trabajo doméstico o la prostitución. Al decir de un funcionario público, "¡desde que hay maquiladoras en Ciudad J uárez, existen menos prostitutas!".

Por otro lado, están aquellos que ven la influencia de las maquiladoras sobre la vida y la composición familiar desde un punto de vista crítico. Estos 
deploran los efectos negativos que el trabajo de la mujer fuera del hogar pudiera tener sobre el bienestar de los hijos y esposos. Creen que al ganar poder económico, las mujeres atentan contra la integridad familiar; las hijas tienden a rebelarse contra los padres, las esposas rechazan los deberes conyugales y la falta de respeto hacia los valores tradicionales se convierte en parte de la vida cotidiana.

Entre los miembros de este grupo existe preocupación acerca de lo que se ha interpretado como promiscuidad creciente y relajamiento moral entre las obreras de maquiladora. Muchos ven evidencia de ésto en el gran número de madres solteras y en lo que se dice ser un incremento de nacimientos fuera del matrimonio entre las mujeres que trabajan en plantas de ensamblaje. Los rumores de promiscuidad, enfermedades venéreas y abortos intencionados entre las obreras, son objeto de atención periódica en la radio y tabloides locales. Ocasionalmente, el descubrimiento de un feto en los sanitarios de una fábrica causa escándalo. Más aún, aquellos que ven estos sucesos como síntoma de decadencia moral, también tienden a ver el trabajo de las fábricas como causa, no como paliativo de la prostitución. Al decir de una joven empleada en una fábrica de componentes electrónicos: "ésto si que me preocupa porque hay gente (especialmente hombres) que la tratan a una distinto cuando se enteran de que trabajo en maquiladora; ¿acaso piensan que si una tiene necesidad de trabajar, también tiene que ser puta?”.

Por otra parte, el trabajo de las mujeres no ha reducido sus responsabilidades con respecto a los quehaceres domésticos. En más de 500 casos estudiados por esta autora, como parte de una muestra de obreras de maquiladora, sólo una fungía como única proveedora mientras que su marido se había hecho cargo por completo del quehacer y del cuidado de un hijo. Como se ha dicho anteriormente, en la mayoría de los casos las mujeres han asumido una doble carga de trabajo, el asalariado y el doméstico.

Por su parte, los gerentes de relaciones públicas y los promotores de las maquiladoras han combatido las acusaciones basadas en el marco de referencia sintetizado arriba, señalando políticas concretas que han sido implementadas por ellos para reafirmar el valor de la femineidad y de la vida familiar tradicional. Algunas compañías ofrecen a sus obreras cursos sobre sexualidad humana, control natal y economía doméstica. Paradójicamente, como incentivos se celebran concursos de belleza anuales en los que se estimula a las obreras a participar. En muchas fábricas, las obreras reciben claveles rojos como símbolo de amistad el día de San Valentín. Muchos gerentes creen que el trabajo de la mujer no tiene que dar como resultado el debilitamiento de los aspectos positivos de las tradiciones, sino por el contrario, se afirma que a través del trabajo asalariado, las mujeres pueden contribuir al bienestar material, educativo y espiritual de sus familias. 
Puede decirse que las perspectivas resumidas arriba revelan profundas contradicciones. Los prejuicios y la falta de información empírica se han combinado para confundir nuestra comprensión del impacto del trabajo femenino sobre la familia, a tal grado que las mujeres se han convertido en el blanco de un folklore naciente y de calumnias misóginas. Lo que distingue estas percepciones es su profunda ambivalencia hacia el trabajo femenino; esto es particularmente obvio en la forma en que se hacen conexiones entre el trabajo fabril y la prostitución. Muchas de estas ideas revelan preocupaciones de la clase media local y no necesariamente la realidad vivida por las obreras de maquila.

Ambas perspectivas conforman un marco ideológico dentro del cual los conflictos, miedos y posibles soluciones suscitadas por el trabajo femenino se manifiestan a pesar de la confusión subyacente.

Para superar estas limitaciones ideológicas es indispensable diferenciar entre el mito y las circunstancias materiales objetivas que rodean al trabajo de maquiladora. Uno de los propósitos de este artículo ha sido el mostrar que el trabajo de las mujeres en operaciones transnacionales de ensamblaje no lleva necesariamente a un incremento de la autonomía femenina. Más bien, el empleo de hijas, esposas y madres en las maquiladoras es, con frecuencia, un síntoma de la vulnerable posición que tanto ellas como sus familias tienen en el mercado de trabajo.

Si bien es cierto que los ingresos de las mujeres se han convertido en un recurso vital para el mantenimiento de quienes dependen de ellas, la evidencia empírica disponible no señala un aumento de la autonomía femenina ni cambios significativos en los valores familiares. Para bien o para mal, los patrones típicos de organización familiar en México persisten entre la mayoría de las obreras de maquiladora. Las hijas solteras viven con sus padres y hermanos y mantienen sus posiciones de dependencia en la jerarquía familiar. Los padres siguen siendo vistos como fuente de autoridad; las madres se hacen cargo de los gastos diarios y se responsabilizan del quehacer doméstico. Así, son ellas quienes reciben directamente gran parte del ingreso de sus hijas. No es poco común el caso de la joven mujer que transfiere su salario mensual a la madre, quien a su vez le confiere a la primera una pequeña asignación para sus gastos.

En verdad que un pequeño número de obreras han establecido otros tipos de relación familiar. Por ejemplo, existen jóvenes que viven alejadas de sus familias y que cohabitan con otras mujeres con las que comparten gastos. Pero tales casos no son comunes, y por lo pronto no puede decirse que en el futuro tales formas de organización familiar reemplazarán a las tradicionales. Se trata, en otras palabras, de casos excepcionales.

Por otra parte, el trabajo de las mujeres no ha reducido sus responsabilidades a los quehaceres domésticos. En más de 500 casos estudiados por esta 
autora, como parte de una muestra de obreras de maquiladora, sólo una fungía como única proveedora mientras que su marido se había hecho cargo por completo del quehacer y del cuidado de un hijo. Como se ha dicho anteriormente, en la mayoría de los casos las mujeres han asumido una doble carga de trabajo, el asalariado y el doméstico.

Durante el período de investigación de campo en Ciudad Juárez hubo oportunidad de conocer a muchas mujeres cuya experiencia ilustra este punto. Margarita González, era una de ellas. Margarita había encontrado empleo en CENTRALAB, una de las mayores empresas manufactureras de Juárez. Después de tres años de trabajo retenía su carácter de trabajadora eventual ya que nunca había firmado un contrato de planta. Cada tres meses el gerente de personal la "invitaba" a firmar su renuncia y al día siguiente le extendía un nuevo contrato por 90 días. Temerosa de perder su empleo si protestaba, Margarita se prestaba al juego aunque esto le alteraba los nervios. Debido a su incierta situación laboral no había adquirido antigüedad en el empleo que posteriormente la podría haber hecho merecedora de las prestaciones que marca la ley mexicana del trabajo.

Margarita trabajaba durante el turno matutino, lo cual hacia necesario que sus dos hijos de edad preescolar tuvieran que quedar durante ese tiempo al cuidado de una señora mayor. Margarita pagaba cien pesos (algo así como cuatro dólares) a la semana por el servicio de niñera. Era éste un gasto considerable ya que ganaba 875 pesos semanales (un poco más de 37 dólares).

Al regresar del trabajo cada día, Margarita recogía a sus hijos y paraba en la tienda del barrio para comprar comestibles e intercambiar opiniones con la dueña del establecimiento. Posteriormente cocinaba y limpiaba su pequeña casa de adobe por la que pagaba 500 pesos mensuales (aproximadamente 20 dólares). Los sábados lavaba y planchaba ropa. Como tenía ambición, también hacía uso de sus conocimientos como peinadora para cortar y arreglar el cabello de sus vecinas.

Por algún tiempo, Manuel, su esposo, también estuvo empleado en CENTRALAB. Mientras que el sueldo de Margarita se utilizaba para pagar los gastos diarios, incluyendo renta, Manuel ahorraba el suyo ya que ambos tenían la ilusión de comprar casa propia. Al ser despedido por CENTRALAB, Manuel no se hizo cargo del trabajo doméstico. Al cabo de una semana de "descanso" comenzó a buscar trabajo infatigablemente, pero no tuvo éxito. Decidió entonces cruzar la frontera ilegalmente y después de algunas semanas encontró trabajo permanente como empleado de mantenimiento en una fábrica localizada en Phoenix, Arizona.

Fueron días de preocupación para Margarita, la cual temía no solamente la pérdida de su propio empleo sino que también dudaba si volvería a ver a su marido. Como muchas otras mujeres en Ciudad Juárez, sabía que muchos 
hombres permanecen indefinidamente en Estados Unidos alejándose por completo de sus mujeres e hijos. Aunque a veces Manuel bebía en exceso y ocasionalmente la golpeaba, Margarita rezaba fervorosamente por su regreso.

Dos meses después, Manuel regresó a Ciudad Juárez con la firme intención de trasladar a su familia a Arizona. Margarita recibió esta noticia con sumo recelo ya que tendría que abandonar definitivamente su trabajo y su familia. Manuel permaneció inflexible. Un domingo por la tarde, un "coyote" amigo los ayudó a cruzar la frontera. Al partir, Margarita me dijo "¡ojalá que Dios nos ayude! Pero ya ve usted que como mujeres siempre estamos a merced de los hombres. Hasta la lavadora, que con tantos sacrificios estaba pagando, tuve que regresar. Y todo por seguir a mi marido...".

El caso de Margarita no es poco común en Ciudad Juárez. Un análisis detallado de esta historia revela varios puntos interesantes. En primer lugar hace notar el carácter vulnerable de las mujeres como empleadas, de quienes se espera la aceptación de situaciones laborales irregulares ya que se sabe cuán fácil es reemplazarlas y cuán graves son sus necesidades cconómicas. Especialmente en la rama de manufactura del vestido, la contratación de personal mediante contratos por obra determinada o temporal son usados como instrumento para mantener "flexibilidad" en la fuerza de trabajo. Desde el punto de vista de los trabajadores, sin embargo, esta política genera incertidumbres y trastornos cotidianos.

En segundo lugar, las presiones familiares hacen que muchas mujeres abandonen sus empleos voluntariamente siguiendo las indicaciones de sus maridos o padres. A veces esta dependencia resulta contraproducente y limita la posibilidad de adquirir conciencia como trabajadoras entre las mujeres. Finalmente, parece estar claro que a pesar de su participación en la fuerza de trabajo industrial, la mayoría de estas mujeres se perciben a sí mismas primero como madres o esposas que como trabajadoras permanentes.

Conviene por último abordar brevemente la relación que algunos ven entre valores sexuales y trabajo fabril. Este es un tema difícil de evaluar. Las entrevistas detalladas que he sostenido con obreras de maquiladora indican que sus percepciones, actitudes y aspiraciones en este renglón se apegan a definiciones tradicionales. El estereotipo de la "mujer decente" pesa gravemente dentro del marco ideológico internalizado desde la infancia por estas mujeres. Para la obrera de maquiladora, el ser confundida con una prostituta es motivo de gran preocupación y genera reacciones defensivas. Aun así, "la decencia" definida en términos convencionales es a veces difícil de preservar en las maquiladoras, ya que existen sutiles formas de seducción que intervienen en el quehacer cotidiano. 
Por ejemplo, aunque su difusión es difícil de medir, los abusos sexuales en el trabajo parecen ser comunes. Numerosos escándalos que involucran la participación de gerentes, empleados de nivel medio y obreras fabriles han sido constatados en los diarios de las ciudades mexicanas fronterizas. En muchos casos, las mujeres se quejan de que tanto supervisores como ingenieros y gerentes suelen solicitar favores sexuales a cambio de estabilidad en el empleo. En otros casos, las mismas obreras ven en su sexualidad el único medio viable para lograr acceso al trabajo; de ahí que se "ofrezcan" a aquellos hombres que están en posibilidad de "ayudarlas". Generalmente estos últimos se encuentran en situación de superioridad económica y educativa. Así, carentes de mecanismos legítimos de poder, las mujeres deben recurrir a su sexualidad para lograr precario acceso al ingreso y al trabajo. Tales circunstancias no son aplicables a los varones (sólo en casos excepcionales) ya que éstos rara vez están en situación tal de vulnerabilidad que deban recurrir a su cuerpo como instrumento de negociación.

Ciertamente, la prostitución es utilizada a veces por las trabajadoras fabriles para suplementar sus ingresos. Sin embargo, esto es más que un tema de ética. Se trata con frecuencia de una viva expresión de la dependencia y débil posición que la mujer guarda en la sociedad. Es conveniente recalcar, a pesar de la gazmoñería provinciana, que el trabajo de maquila no ha generado, hasta ahora, situaciones que permitan a la mayoría de las mujeres obtener mayor autonomía personal o familiar. Los bajos salarios, la falta de seguridad en el empleo y las frecuentes deficiencias en las condiciones laborales, colocan al empleo en maquiladora, apenas un escalafón arriba de las condiciones que propician la prostitución y la destitución económica. Por lo tanto, la solución a estos problemas no radica en la crítica moral, sino en la reforma de los mercados de trabajo que persisten a lo largo de la frontera mexicana.

\section{CONCLUSIONES}

Este ensayo constituye un intento preliminar por abordar un conjunto de factores que explican o afectan el empleo de la mujer en la industria maquiladora fronteriza. Para comprender la expansión del programa de maquiladoras no es suficiente parar mientes en las políticas delineadas por el gobierno mexicano, sino que es necesario tomar en cuenta aspectos tales como la creciente fluidez del capital transnacional y la posición que guardan ciertas industrias en el contexto mundial. La búsqueda de bajos salarios, abundante mano de obra y una situación política estable, son algunas de las variables que han estimulado el traslado de procesos productivos de países hegemónicos como Estados Unidos a zonas periféricas y semiperiféricas como la frontera mexicana.

Algunos funcionarios públicos en México han afirmado que el crecimiento de la industria maquiladora es parte fundamental de la estrategia nacional de desarrollo. Sin embargo, cuando se observa la historia de tal industria se 
perciben notables limitaciones e inconsistencias. El suponer, por ejemplo, que la industria de maquila es un vehículo adecuado para el adiestramiento tecnológico y la capacitación obrera no toma en cuenta los procesos de descalificación y feminización del trabajo a los que alude este artículo. Si bien es cierto que las maquiladoras han generado cientos de miles de empleos en poco más de una década, con la consecuente derrama económica, conviene en el futuro hacer un cuidadoso análisis del carácter de tales empleos. Como hemos visto, muchos de éstos (especialmente aquellos localizados en la industria de la confección) son transitorios, mal remunerados y están aparejados a agotadoras cuotas de producción.

La coexistencia del trabajo fabril femenino y las altas tasas de desempleo y subempleo masculino que caracteriza los mercados locales de trabajo en la frontera mexicana no debe tomarse a la ligera. Esta combinación genera falsas imágenes de crecimiento económico sin un mejoramiento real de las condiciones materiales en las que viven cientos de miles de familias trabajadoras.

El éxito de un programa industrial no debe juzgarse únicamente en cifras numéricas de carácter impersonal sino que también deben considerarse los costos sociales y políticos que genera. Sin planeación adecuada, el programa de maquiladoras puede convertirse en un instrumento de acentuación de la dependencia y no en un adecuado vehículo para el desarrollo nacional integrado.

\section{BIBLIOGRAFIA}

BUSTAMANTE. I.. Maquilaloras: A new face of International Capitalism on Mexico's Northern Frontier. Trabajo presentado a la VI Reunión Nacional de la Latin American Studies Association, Atlanta, Georgia, 1976.

BAERRESEN, D., The Border Industrialization Program of Mexico, New York, 1971

BAUDOUIN, T.. M. Collin, y D. Guillem, Women and Inmigrants: Marginal. Workers? en: The Resurgence of Class Conflict in Hestem Liurope Since, Crouch, C. y Pissorno, A., Eds., Holmes and Meier Publishers, New York, 1978.

BRAYERMAN, H., Labor and Monopoly Capital, Monthly Review Press, New York, 1974.

BAYER, I., Lnidad Coordinadora para el empleo, capacitación y adiestramiento, Gobierno Mexicano, Discurso frente a la convención regional de asociaciones de maquiladoras de Ciudad Juárez, Chihuahua, México, febrero 9 de 1979.

BUSINESS WEEK, abril 26, 1976.

CAMPERO, M. P. y C. A. Cuerrero, Reflexiones sobre la participación de la obrera en la industria maquiladora en Mexicali, Baja California y su impacto en la estructura familiar. Trabajo presentado en el Primer Simposio Centroamericano de Investigación sobre la Mujer, México, 1977.

CAULFIELD. M. D., Imperialism, the family and cultures of resistance, en Socialist Revolution, No. 20, pp. $67-85,1974$.

CORNELJUS, W. Mexican Migration to the United States (With comparative reference to caribbean-Basin migration). Trabajo No. 2, Center for United States-Mexican Studies, University of California, San Diego, 1979.

DEERE, Carmen Diana, J. Humphries, y M. Leon, Class and Historical Analysis for the Study of women and economic Change. Trabajo presentado para The Role of Women and Demographic Change Research Program, OIT, Ginebra, 1978.

EDWARDS. R. C., Reick, M. y Ciordon, D. H., Eds, Labor Market Segmentation, Lexington, 1975.

ELECTRONIC NEWS, enero 10, 1977.

ENC,ELS, F., The Condition of the Working Class in England, Henderson, W. O. y Chaloner, H., Edts. y Traductores, Universidad de Stanford. Stanford, 1958. 
FERNANDEZ, Kelly, M. P., Mexican border industrialization, female labor force participation and migration. Trabajo presentado en la Reunión Anual de la American Sociological Association, San Francisco, 1978.

- Chavalas de Maquila: A study of the composition of the female labor force in Ciudad Juarez off shore production plants. Tesis Departamento de Antropología, Universidad de Rutgers, 1980a.

- Francisca Lucero: A profile of female factory work in Ciudad Juarez, resumido bajo el título La realidad de las maquiladoras en: Rerista de la Fundacion Interamericana, $1980 \mathrm{~b}$.

FERBER, M. H. y H. M. Lowry, Women: the new reserve army of the unemployed, en: Sings, Vol. I, No. 3 , 1976.

FROBEL, F., J. Hinrichs y O. Kreye, Tendency towards a new international division of labour; World wide utilization of labour force for world market oriented manufacturing, en Economic and Political Weekly, 1976.

- The new international division of labour, en Social Science Information, Vol. 17, No. 1, 1978.

GONZALEZ Salazar, G., Participation of women in the Mexican labor force, en Sex and Class in Latin America, Nach, J. y Safa, H. I., Eds., New York, 1976.

HELLINER, G. K., Manufacturing exports from less developed countries and multinational film, en The Economic Journal, No. 83, pp. 21-47, 1973.

KONING, W., Efectos de la actividad maquiladora fronteriza en la sociedad mexicana. Trabajo presentado en el Simposio Nacional sobre Estudios Fronterizos, Monterrey, Nuevo León, México, 1979.

KUZNETS, D., Demographic aspects of the size distribution of income: An exploratory essay, en Economic Development and Cultural Change. No. 25, pp. 1-94, 1976.

LADMAN, J., Economic impact of the Mexican Border Industrialization Program: Agua Prieta, Sonora. Center for Latin American Studies, Arizona State University, Tempe, 1972.

LARGUiA, I. y J. Dumoulin, Aspects of the condition of women's labour. en NACLA's Latin America and Eimpire Report, IX, 6, 1975.

LIM, L. Y. C., Women workers in multinational corporation: The case of the electronics industry in Malasya and Singapore. Michigan Ocasional Paper No. IX, 1978.

MARTIN, K. y Tallock, P., Trade and Developing Countries, Croom Helm, Londres, 1977.

NEWTON, J. R. y F. Balli, Mexican in bond industry. Trabajo presentado en el Seminario sobre "North South Complementary Intra-Industry Trade", UNCTAD, Conferencia de las Naciones Unidas, México, 1979.

NACLA's Latin America and Empire Report, U. S. Runnaway Shops on the Mexican Border, IX, 7, 1975.

- Capital's flight: The apparel industry moves south, XI, 3, 1977a.

- Electronics: The global industry, XI, 4, $1977 \mathrm{~b}$.

$\mathrm{NASH}, \mathrm{J}$., Certain Aspects of the integration of women in the development process: A point of view. Trabajo presentado durante las sesiones de las Naciones Unidas, Año Internacional de la Mujer, New York, 1975.

NAYAR, D., Transnational corporations and manufactured exports from poor countries, en Economic Journal, No. 88 , pp. $59-84,1977$.

PARNES, H. S., Labor force and labor markets, en Review of Industrial Relations Research, Vol. I, Industrial Relations Research Association, University of Wisconsin, Madison, 1970.

PEARSON, R. y D. Elson, Internationalization of capital and its implications for women in the Third World. Trabajo presentado en el simposio sobre la subordinación de la mujer, Institute for Development Studies, 1978:

PORTES, A., Unequal exhange and the urban informal sector en Portes, A. y Walton, J., World Exchange and Domination, Essays in the Political Economy of Development, Academic Press, New York, 1981.

SAGA, J. I., Class Consciusness Among Working-Class Women in Latin America: Puerto Rico en Sex and Class in Latin America, Nash, J. y Safa, H., Eds., New York, 1976.

- Multinationals and the employment of women in developing areas: The case of the Caribbean. Trabajo presentado en la Reunión Anual de la America Anthropological Association, Cinncinati, 1979.

- Women production and reproduction in industrial capitalism: A comparison of Brasilian and U.S. factory workers, mimeo, sin fecha.

SCOTT, L. y J. Scott, Women, work and the family, Rinehart and Wiston, New York 1978. Schmink, M., Women men and the Brazilian model of Development. Trabajo presentado en la reunion anual de the Latin American Studies Association, Pittsburgh, 1979.

SIEGEL, L., Delicate Bonds: the Electronics Indwstry, Pacific Studies Center, Berkeley, California, 1981.

SOUTHEAST ASIA CHRONICLE, Changing roles of S. E. Asian women. The assembly line and the social manipulation of women on the Job, 66, 1979.

TRAITENBERG, R. y J. P. Sajhau, Las empresas transnacionales y el bajo costo de la fuerza de trabajo en los paises subdesarrollados, World Employment Programme Research, Trabajo No. 5, OIT, Cinebra, 1976.

UGALDE. A., Regional and Political Processes and Mexican Politics on the Border en Views Across the Border, Ed., S. Ross, University of New Mexico Press, 1978.

UNIVERSITY OF TEXAS, El Paso, The Ciudad fuarez plan for comprehensive socioeconomic development: A model Northern Mexico Border Cities, 1977.

URQUIDI, V. y S. Méndez, Economic Importance of Mexico's Northern Border Regions, en Views Across the Border, Ross, S., Ed., University of New Mexico Press, Albuquerque. 1978. 